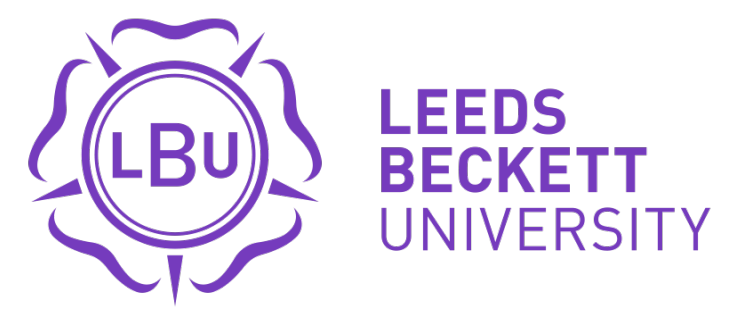

Citation:

Caruana, V (2014) Re-thinking global citizenship in higher education: From cosmopolitanism and international mobility to cosmopolitanisation, resilience and resilient thinking. Higher Education Quarterly, 68 (1). 85 - 104. ISSN 0951-5224 DOI: https://doi.org/10.1111/hequ.12030

Link to Leeds Beckett Repository record:

https://eprints.leedsbeckett.ac.uk/id/eprint/344/

Document Version:

Article (Updated Version)

Please note this is the author's final manuscript and may differ from the published version which should be used for citation purposes

The aim of the Leeds Beckett Repository is to provide open access to our research, as required by funder policies and permitted by publishers and copyright law.

The Leeds Beckett repository holds a wide range of publications, each of which has been checked for copyright and the relevant embargo period has been applied by the Research Services team.

We operate on a standard take-down policy. If you are the author or publisher of an output and you would like it removed from the repository, please contact us and we will investigate on a case-by-case basis.

Each thesis in the repository has been cleared where necessary by the author for third party copyright. If you would like a thesis to be removed from the repository or believe there is an issue with copyright, please contact us on openaccess@leedsbeckett.ac.uk and we will investigate on a case-by-case basis. 


\title{
Re-thinking Global Citizenship in Higher Education: From Cosmopolitanism and International Mobility to Cosmopolitanisation, Resilience and Resilient Thinking
}

\author{
Viv Caruana, School of Education and Childhood, Leeds Metropolitan \\ University, v.caruana@leedsmet.ac.uk
}

\begin{abstract}
Developing graduates as global citizens is a central aim of the internationalised university of the $21^{\text {st }}$ century. International student mobility premised on notions of cosmopolitanism is regarded as a key component of the student learning experience. Yet there is little evidence to suggest the benefits of international mobility for intercultural understanding, which is an essential quality of the global citizen. This paper reports the findings of a Higher Education Academy-funded project exploring how students draw on their diverse backgrounds in developing resilience within multicultural learning environments. The research findings suggest that student diversity provides a rich source of lived experience that can be harnessed as a resource in developing graduates as global citizens. The paper therefore suggests that institutions re-conceptualise global citizenship as a concept embracing diversity, belonging, community and solidarity and support the development of pedagogies that embrace cultural biography and storytelling.
\end{abstract}

\section{Introduction}

The internationalised university of the $21^{\text {st }}$ century is characterised by ethnic and cultural diversity reflecting global flows of international students and domestic multiculturalism. Intercultural understanding is an important element in delivering a learning experience that prepares graduates for working and living in a global world. While universities strive to increase international student mobility as a means of developing the global citizen, evidence suggests that voluntary social segregation among and between diverse groups of home and international students, reflecting fundamental issues around intercultural understanding is a common phenomenon on university campuses worldwide (Caruana and Ploner, 2010; Harrison and Peacock, 2010; Volet and Ang, 1998). Based on students' accounts of their resilient responses to the challenges encountered in their journeys to, and experience of higher education this study shows that the diversity of the student body on university campuses provides a rich source of lived experience in cultural boundary-crossing that could be harnessed as a resource in promoting intercultural understanding and, in turn, developing graduates as global citizens. In this way global citizenship education would transcend the boundaries of the mobility model acknowledging and responding to a process of 'cosmopolitanisation' in which the lifeworlds of different peoples converge in a social landscape where the local and global are increasingly interconnected and interpenetrating (Beck, 2006). 


\section{'Promoting Students' Resilient Thinking in Diverse Higher Education Learning Environments': A Narrative Approach}

This article draws on the findings of a research project funded by the Higher Education Academy's subject centre for Sociology, Anthropology and Politics (C-SAP) 'Promoting students' resilient thinking in diverse higher education learning environments' which was conducted across three tertiary institutions based in the North of England. In examining approaches to resilience in higher education, Walker et al., (2006, p. 251) define it as the '... ability to recover rapidly from difficult situations' and '...capacity to endure on-going hardship in every conceivable way'. Other authors speak of 'the action or act of rebounding or springing back; the quality or fact of being able to recover quickly or easily from, or resist being affected by, a misfortune, shock, illness, etc.' (Resilience, 2010, quoted in Mercer, 2010, p. 1) or as ‘a basic strength underpinning positive characteristics within a person's emotional and psychological make-up’ (Reivich and Shattle, 2002, p. 59).

The project aim was to explore how social science students draw on their diverse backgrounds in developing resilience within multicultural learning environments. The three institutions, within close geographical proximity included a research-intensive university, a modern 'widening participation' university and a further education college delivering foundation degree programmes. This selection was designed to capture experience across a range of institutions operating in different contexts vis-a-vis institutional culture, mission and profile but located within similar socio-economic, multicultural communities.

An open call 'Promoting students' resilient thinking in diverse higher education learning environments - Tell us your views and enhance the learning experience' was distributed to social science students, via course leaders and tutors, university and students' union social networking sites, and various student access points across campuses. Students were asked to 'take part in interviews to discuss the challenges they face and explore the personal resources, resilient traits, and external sources of support that enable them to cope in diverse learning environments.

The study design reflects a recent trend towards qualitative approaches in understanding resilience and resilient thinking. This trend suggests that universalistic and deterministic conceptions of resilience as 'inherent' or 'pre-existing' personal traits of an individual or group, are giving way to recognising the influence of the socio-cultural context of locality and community. At the same time it is acknowledged that resilience and resilient thinking involve a continuous process of development and negotiation of identities and autonomous selves (Chan, 2001; Holliday \& West, 2010; Luthar, 2003; Mercer, 2010; Ungar, 2003; Walker et al., 2006).

A narrative approach to semi-structured interviews was adopted in order to procure 'stories' and capture lived experience through an empathetic two-way conversation. To facilitate the conversation interviewers were drawn from members of the research team who had themselves experienced international study or university life as 'non-traditional', 'widening participation' students. The interviews were loosely structured around notions of 'home and 
away', 'here and there' enabling students to reflect on their personal journeys, to consider how decisions to come to university had been influenced by what was going on around them and to share their expectations and experiences of life at university and in the surrounding community. In privileging the biographical the interviews elicited individuals' everyday experiences of cultural difference, and how it is construed, within a framework of resilience and resilience thinking, over time and space.

Interviews were audio-taped, transcribed and subjected to inductive thematic analysis. The first reading of the data identified major issues and key words and phrases in order to get a sense of themes embedded in the data. Subsequent readings involved disaggregation of the data to support an iterative process of development and refinement of themes. The text was deconstructed in order to identify statements within individual transcripts and across the data set that could be grouped together under emerging themes. Individual statements were then consolidated to develop a close fit between the data and the themes and to avoid an array of idiosyncratic groupings. In the final stage of analysis quotations to illustrate themes were selected. Since many participants were drawn from study programmes with small cohorts demographic detail has been deliberately limited in reporting findings and the data 'cleaned'. For example, the names of cities or countries have been replaced by regions as appropriate, in the interest of participant anonymity and participants are identified by pseudonym, gender and place of birth.

21 students across the three institutions responded to the invitation to take part in the study. A striking feature of the participant profile is their cultural, social and ethnic diversity. The vast majority are migrants originating from various parts of Europe, Asia, Africa, and the Middle and Far East. They either came to the United Kingdom (UK) at an early age with their families or re-located independently and established their own families in their new place of residence over a period of about ten years. All participants can be classed 'mature students' ranging in age from their early twenties to late thirties. A wide range of disciplines within the social sciences (including sociology, politics, criminology, cultural anthropology, tourism, applied global ethics, business and management, urban planning and information and computing technology) are represented at foundation, undergraduate and postgraduate levels of study.

\section{Background and Context: Global Citizenship and Cosmopolitanism}

Global citizenship is a concept that is abstract and ill-defined. Those who embrace the idea tend to perceive it in expansive terms, encompassing ways of thinking and living that evolve over time. When conjoined with the notion of belonging, global citizenship can extend inwards as well as outwards 'These days you don't have to leave home...to see yourself as a global citizen in continual formation' (Schattle, 2007:3). Intercultural sensitivity - embracing

awareness as cognition and competence as behaviour drawing on attitudes, knowledge, skills and action propensities to engage with difference - is vital for effective interaction, dialogue and participation in the multicultural societies that constitute the globalised world of today and is in turn, a central component of global citizenship (Barrett et al., 2011; Chen and Starosta, 2000). 
Schattle (2007) suggests that international travel, study or work and experience close to home in diverse communities, are appropriate experiences for expanding cultural horizons and developing intercultural understanding. Others claim that international mobility enables students to develop the capacity to engage in transformative experiences with cultural 'others', a benefit largely attributed to facilitating a shift in students' frames of reference (Bennett, 2008; Killick, 2012). However, Savicki and Selby (2008) argue that there is insufficient knowledge and understanding of how intercultural competence, growth and transformation occur as a result of mobility. Similarly, evidence from students, mobility managers and employers of how study abroad enhances graduate employability is sparse (King et al., 2010) Yet the norm of mobility provides such a powerful underpinning for the values and assumptions of global perspectives, that it has become an almost exclusive frame of action, perception and identification of the global citizen (Hedetoft, 2011; Schattle, 2007; Rhodes et al., 2008).

Global citizenship education in the UK HE sector may be informed by the philosophical, normative form of cosmopolitanism: a values-based approach with allegiance to humanity and a strong emphasis on human rights (Beck, 2002; Jakubowicz, 2011; Pieterse, 2006; Saito, 2011 Hannerz, 2006). However it is argued here that, given the one-sided view of the benefits of mobility, any normative intentions are far outweighed by the influence of pragmatic, human capital and sometimes élitist approaches to cosmopolitanism.

Openness as the preserve of travellers represents a form of élite cosmopolitanism once associated directly with privilege, but nowadays more associated with notions of professionalism with the growth of transnational occupations and the neo-liberal movements of people as 'human capital'. Élite cosmopolitans have weak attachments with people in countries of primary residence and strong attachments that traverse group boundaries. They move within self-enclosed enclaves and transnational networks of élite co-cosmopolitans (Jakubowicz, 2011 Pieterse, 2006 Saito, 2011; Hannerz, 2006; Szerzynski and Urry, 2002).

In the pragmatic or instrumental conception of cosmopolitanism openness is distinguished by the ability to make one's way in a different culture. A habitual readiness to cope with encounters with cultural diversity derives from self-confidence and the application of the skills of listening, looking, intuiting and reflecting on experiences. Unlike the tourist who simply consumes places and goes back home, who is incompetent and uninterested in participation and the 'exile' whose emotional attachment is to home, who takes no pleasure in participation that is seen as a necessity, a cost to be incurred, the pragmatic cosmopolitan is willing to engage with difference but can withdraw from engagement without compunction (Hannerz, 2006; Parrish and Linder-Van Berschot, 2010; Thomas et al., 2006). 
Global citizenship education premised on international mobility may be ineffective in the development of openness towards divergent cultural experiences and the ability to engage with cultural 'others', which are the pre-requisites of global citizenship. Encountering otherness abroad may involve rejection or narrow selection rather than openness, since the 'surrender' to openness is situational and dependent on the nature of intercultural contact. Allport (1979) maintains that prejudice is only reduced by sustained intercultural contact that reaches below the surface and involves groups of people who enjoy equal status in the pursuit of common goals. In the absence of such conditions people can be pleased with their experiences and personal levels of connoisseurship with regard to cultural diversity, without proceeding beyond self-indulgence and without any sense of responsibility to humankind that prompts activism (Hannerz, 2006; Westrick, 2005).

A more profound issue with the 'mobility' model is that whilst acknowledging that globalisation provides access to a wider cultural inventory which can be harnessed in the contexts of work and play, it fails to recognise that globalisation also means that a larger part of the cultural inventory has access to the individual in their local neighbourhood and workplace. Confronted with the everyday challenges of diversity at home, which constantly demand new modes of thought and action, the individual might prefer not to bother with diversity but somehow it insists on attention, all too often prompting retreat into a cycle of ever-decreasing contact to the detriment of cultural learning opportunities (Hannerz, 2006; Shannon-Little, 2013).

In the final analysis, global citizens do require the ability to work, play and live somewhere other than their land of birth but global citizenship is not simply a matter of accumulating multiple addresses through international outward mobility. Rather, cosmopolitanism and localism exist as two sides of the same coin, always in conversation and, therefore, global citizenship is about being proactive, being capable of making change happen and living ethically in both the global and the local, the distant and the proximate simultaneously (Szerzynski and Urry, 2002; Thomson and Taylor, 2005; Bryant, undated).

\section{Re-conceptualising Global Citizenship Education: Where the 'Cosmopolitan' meets the 'Resilient'}

An open invitation to students to participate in research focused on resilience and resilient thinking in diverse higher education learning environments prompted rich responses from individuals who were culturally, ethnically and socially diverse. The stories of their journeys to higher education, the challenges they faced and their responses suggest that resilience and resilient thinking are intertwined with conceptions of cosmopolitanism that transcend the boundaries of the élite, pragmatic, human capital norms that inform current global citizenship education. 


\section{'The Age of Second Modernity': Risk and Duress}

Beck (2002) argues that in the post-war period the age of 'first modernity' is evolving into 'second modernity' where the simple, logical and therefore calculable is giving way to complexity, ambiguity and incalculable uncertainty. In the 'second modernity', the transition from youth to adulthood, which in the early post-war Western world assumed a relatively predictable and linear trajectory based on household formation, education and paid work, is giving way to the 'do it yourself biography', the 'risk biography', the 'tightrope biography' where circumstances demand quick decisions made without guarantees (Beck 2002; Woodman, 2009). The majority of participants in this research, study in the UK but originate from regions beyond the Western world. Some of their stories convey notions of 'risk biography' in a world where incalculable uncertainty requires heightened self-reflexivity in order to avert the potentially dire consequences of hypothetical risks that have become real. The reality produces an overwhelming compulsion to act, which prompts border transcending behaviours that will ultimately connect individuals to others with whom they otherwise would have had no contact. The encounter with risk contrasts with what Beck (2006) refers to as the 'luxury risks' of the Western world and represents a form of 'enforced cosmopolitanisation' or 'cosmopolitanisation under duress'. The emergent global citizen in this scenario is likely to assume a persona and disposition towards the world that is quite different from that assumed by the global citizen whose international experience derives from a desire to enhance their graduate employability and future career prospects.

Three participants from various parts of the African continent reflected on quite violent experiences and threats to their and their families' lives that were linked to individual political activism, personal assault or war.

...late in my life I developed an interest in the public affairs of our country...towards the end of 1999 the new Party was born...it touched the hearts of our, of people my age. I joined them and became an active member...I became a political activist and ended up putting my life in danger...to try and save myself and you know, my life, I looked into the future and decided to flee the country... (Chenzira, male student, Africa)

While decisions are made in the moment the consequences can be not only harsh, but enduring:

I had a job in another town which was a bit smaller than the one I was living in [then] the war broke out...when there is a war...bombing...you just wake up and start running... That's how I lost my parents...for a year I did not know whether they were alive or not...After a time we find ourselves in [African country]...we lived there for seven years...in a refugee camp...[it] was like open bush...just a forest...you don't know what to eat, you don't know where to go even for simple things like toilet...You just give your application to UN HRC...you don't choose where you are going to...you are like desperate. (Nanny, female student, Africa) 


\section{Perceived 'Risk Factors' and Cultural Dissonance}

In relating their experience of life and study in the UK participants reveal the discomfort and frustration of functioning in an unfamiliar, often unpleasant and sometimes hostile, social environment which manifests in a host of different ways challenging the sense of self, causing anxiety in the absence of new coping strategies and re-negotiation of identity (TingToomey and Chung, 2012; Zaharna, 1989). In this study, 17 participants (80\%) alluded to the challenges of survival in an unfamiliar academic environment and culture. Language and communication issues and underlying fears of humiliation, despite high educational achievements in prior cultural contexts, are discussed by five participants:

Here in semester one I did not know what to say in class...I didn't want to look stupid but...at school I was head of the school parliament... and always had lots to say... (Alyona, female student, Eastern Europe)

It was really difficult for me to get into understanding...how people...created sentences... at school you are taught the grammar...but it was really difficult to speak to people or understand because it is so different to what I had learnt in my country... (Eva, female student, Eastern Europe)

The challenge of balancing home, family and academic commitments is another popular theme expressed by both male and female participants:

...it's just constantly juggling kids and uni. work and looking after the home, looking after my husband...it's really difficult to actually get motivated to actually get your books out every night and do what needs to be doing... (Norma, female student, Scotland)

...I've got now three kids - two daughters, one son...it's not easy to study, look after a family and I...run my own business here...a pizza shop...last year while my wife was pregnant...every morning I have to take my kids to school. After that I come home, I see what my wife needs to cook, what I have to bring for her...Three o'clock I have to bring my kids from school... Everybody has story what he have done all day and I can't tell my daughter "I don't want to listen to you” even I feel sleepy I have to listen to my daughter...evening time I have to go to my shop... (Abdo, male student, Middle East)

Four participants highlighted the importance of prior learning experiences in alternative cultural contexts in shaping their perception of academic culture and their experience of learning in the host country:

...here you have everything, in the States you have everything to bring up a child to learn and all that. But an African background is strict...here...you see people don't take school seriously...they're not in class on the exam day. It doesn't happen back in Africa...you get punished for that, like really, really punished you get rewards when you do good... So you take education seriously... (Jamal, male student, Africa) 
While participants' stories evidence an array of challenges within the context of their academic endeavours, intercultural encounters within the broader social context beyond the academic environment seem to be both more complex and significant in undermining the sense of self and hindering academic performance. Simply living in the UK presents difficulties that can endure over lengthy periods of time. Anti-social behaviour and outright prejudice whilst experienced, are relatively rare. However, friendship development is hampered by a deficiency of cultural knowledge and cultural dissonance that operates in two directions between participant and the surrounding community:

When you come here actually you erase everything...nobody knows what you have been through, or, you know, what kind of person you are and what you are capable of and what you are not capable of...Your life started as if you were born twenty five years old and just in [city, North East England] ... (Adeel, male student, South Eastern Europe)

...there was like, some cultural and religious difficulties that are still there...I have my boundaries in terms of you know, gender relations and others... when you talk to somebody you need to explain that you know, this can only be friendship...otherwise you might see them, they might be expecting from you another step...Many people when you express yourself as a Muslim has...no idea about Islam...people have difficulties to understand and you can't expect them to be experts in every issue... (Adeel, male student, South Eastern Europe)

While some participants refer to issues around peers' lack of knowledge of their culture, others perceive their difficulties as being rooted in their lack of experience and inability to comprehend UK culture:

...although you speak English, being white South African...not Afrikaans background you're really different...you don't know the history, you don't know the celebrities...I sometimes still feel isolated because I don't know personalities or famous people that were around when my peers were younger. (Naledi, female student, Africa)

Back home we are like united, community is one...but here is like a closed family...You don't even know your neighbour, not talked to...it was really tough...I was confused asking myself...every day how this society works, how people think, why people...throw eggs...tell us to go back...When I came to college I started reading...to know how people function, how this society functions... (Nanny, female student, Africa)

\section{Resilience - the 'Protective Factors'}

The raw material of resilience is intellect, physical robustness and emotional stability. How these interact with the surrounding network, culture and practical situations determines the level of resilience based on the 'protective factors' of external support (family, friends, teachers etc.), internal support (abilities and skills and learning to develop them) and 
existential support (meaning, values and faith) (Gunnestad et al., 2010; Gunnestad, 2006). The interplay of support mechanisms is complex and culture-bound. The search for the meaning of life and personal meaning (self-knowledge and self-esteem to improve the human condition) begins in adolescence and is highly dependent on social interactions with nurturing adults who themselves provide personal valuations and support in the face of ontological anxiety. The values nurtured through these interactions and life experience vary between cultures, for example, the values of responsibility, discipline and perseverance may be deeply ingrained in traditional Chinese culture but not so deeply embedded in Western cultures. Similarly, faith or spirituality, belief in a personal God, which provides meaning for actions will vary between cultures and ethnic groups depending on the level of secularisation of society (Beck, 2006; Wong and Wong, 2012). Seventeen (80\%) participants in this study alluded to 'protective factors' largely in the form of internal support mechanisms, such as the ability to maintain a sense of perspective in the face of adversity, learning from observing others, setting clear goals and being confident, determined and persevering. For over half of the participants, motivation was a key factor sometimes fuelled by the influence of, or desire to make a difference to others.

Personal achievement was the driving force for three students:

I've always been motivated...I thought after boarding school I'd graduate and just leave it...but I thought no, I don't want to end my education...I'm gonna be the first person in my family to actually go to university...that's what motivated me (Zuha, female student, Iran)

Three students were quite profoundly inspired by notions of transforming the lives of others in their homeland:

...when I go back I will be going back as a different person altogether...the difference is I will make a very good role model to so many struggling who have similar backgrounds...I will be able to contribute meaningfully to the cause of...my people...people with similar backgrounds...I will be telling them...to be resilient and stand up to the challenges of life... (Chenzira, male student, Africa)

The most prevalent source of motivation was however, parents and particularly mothers, some of whom felt that they had missed opportunities in their own lives and others who had graduated and were striving to provide the same opportunities for their families:

...my Mum's a nurse ...she went to uni....so when she left South Africa she definitely wanted us to go to university...My Mum...she went to work and we lived in the suburbs...I went to an all-girls school, my sisters and I...in South Africa you pay for your own education...so she was a single parent and she was paying for four of us... (Kasigo, female student, Africa)

...my Mum...says whatever you want to do I'm going to support you in it...she is really happy that I'm going to uni. 'cos she never got the chance...she's really like 
'I'm so proud of you...because it's something that I could never have done'... (Norma, female student, Scotland)

Participants' comments about their relationship with parents generally suggested that rather than simply being a source of external support in difficult times, their influence was such that aspirations for their offspring had effectively been internalised. As nurturing adults parents provided positive role models encouraging the development of personal skills and attributes to cope in times of challenge:

...my family and I are really close-knit...the four of us, the nuclear family since we emigrated...Mum always wanted me to go to university, me and my sister...she'd done one year of uni. and then dropped out to be with my Dad... My Dad lost his job...had knock back after knock back [but he still tries to see] where he can go from here...Mum is quite ill...but she manages to get up every day regardless of how painful it is and earns money to keep our family going... (Naledi, female student, Africa)

In contrast to these strong connections with family, only two participants made very fleeting references to peer friendship as a source of support. Indeed two others cited very practical reasons for not regarding friendship as a significant coping mechanism:

I didn’t necessarily...come to university to make friends...I've had friends all my life and they don't really help. They're not the ones doing your university assignments...I came here to study so that's what I concentrate on. (Tashia, female student, England)

You need your mother to come and just go, you know, "oh, it’s going to be alright”...Although your friends tend to do it sometimes, but the thing is downtimes come at the same time for everybody...they won't be able to console you that much anyway, so yeah, I found that really hard (Agrajeeta, male student, Middle East)

Existential support in the form of faith and religion were mentioned by two students including Kagiso from South Africa, who came to England with her mother and three sisters some years ago:

Prior to uni. my sisters and I, like, we used to sing at a church...but since starting uni. it's been really hard to go to church...you can still turn to it when you're at home and you pray even if you're on your own or just put a gospel song on and feel uplifted...if you can see an end goal the other things are just obstacles to the end goal so you don’t...get easily weighed down, I think, if you've got some sort of faith... (Kasigo, female student, Africa)

\section{Challenging the Local-Cosmopolitan Dichotomy: 'Detached Stayers', 'Attached Leavers' and 'Rooted Cosmopolitans'}

Current research into the place of mobility and travel in youth transitions to adulthood, challenges the traditional cosmopolitan-local dichotomy rooted in the work of Merton (1957), 
which casts locals as being confined to their local community and cosmopolitans as oriented towards the wider world. Rather than counterpoise cosmopolitanism and localism as fixed aspects of identity, these concepts are viewed as strategies or tactics to be employed in transitions from youth to adulthood. In some ways, tensions between competing forces in relation to notions of home, tradition and fixedness on the one hand and of mobility, escape and transformation on the other (Henderson et al., 2007) are evident for participants in this study.

The testimonies of two students in particular, one UK born and the other of Afro-Caribbean origin reveal a need to 'get out' to 'get on' which is characteristic of 'emancipatory cosmopolitanism', a cosmopolitanism of experience and action, a cosmopolitanism that is reflexive in practising and making world citizenship (Pieterse, 2006; Thomas et al., 2006; Thomson and Taylor, 2005). Rather than remain the 'detached stayer' feeling trapped and dissatisfied, they choose to take an option that at least offers some prospect of 'emancipation' from home communities that are incongruent with their emerging self-image:

...came to [city, North East England] just to get away from everything...to, have a fresh start... where I normally hang out...it's basically a council estate...merging of two schools was really difficult...I just didn't learn much... '[In my neighbourhood] they try to go out every weekend and get drunk or they’ve got kids...I still speak to a few people...they're working full-time...labour jobs...I think it was just a new experience....Moving....if I stayed in [city, North West England] I just would have got pulled down... (Tim, male student, England)

...my Dad is from South Africa and my Mum's from the Caribbean...so it's not as if I'm tied to only British culture...in the community that I'm from it's not exactly cool to be a geek... or be so motivated...newer immigrants, they tend to be more committed towards education and improving...but the people that have been here longer...no matter what ethnicity, they tend to take the opportunities here for granted... (Tashia, female student, England)

Despite a perception of having adapted to UK culture two students' testimonies are consistent with the notion of the 'attached leaver' since they retain a strong attachment to their home country despite extensive travel and engagement with the host culture:

...I have had a good, good social life in [city, home country]...I always need to see friends, go with them with breakfasts and late nights and everything...it was built up, you know, six, seven years in [city, home country]...the relative relations, family, extended families and many things... when you've got a very good friendship back home you don't want to spend ages to establish a new one here... (Adeel, male student, South Eastern Europe)

...I've many times in some European countries with my family... I've been three times to Germany... we stay there over two months every year... When I came to London...I couldn’t meet English people... all the people there are international 
people, even in my class there was too much Arabic students with me...Then I ask my cousin...He told me "Go to [town, South East England] and study there"...It was good for me...Then I moved to [town, North West England] to study my foundation year... Now I want to finish my two years here then back home, that's it... I don't want this again, to be abroad again... (Agrajeeta, male student, Middle East)

Gunnestad (2006) claims that those who master the rules and norms of a new culture through finding contact points between cultures are more resilient than those who adhere exclusively to their own culture or those who become highly acculturated. Participants in this study reveal how the relationship between 'home and away' is complex, dynamic, and shifting with the passage of time. Nonetheless, resolution can be found with a determination to establish authentic 'contact points'. In contrast to élite conceptions of cosmopolitanism these participants can be characterised as 'rooted cosmopolitans' who develop a sense of being at home in more than one place, which stems from a process of putting down roots rather than being forever rooted (Hannerz, 2006; Saito, 2011).

Strong attachments nurtured over an extended period of time can be challenged:

...the longer you live somewhere else, the longer you find you are away from your friends, even though they are still your friends...the relationship you have with them is nowhere near as intimate and as deep as it was before... (Eva, female student, Eastern Europe)

Yet 'epiphany moments' (Denzin, 1989, p. 170) can occur in how the relationship between 'home and away' is perceived through developing 'contact points' that transcend the cultural boundaries of intellectual curiosity to engage the passion for the aesthetic:

...you come to the realisation that you don't have to dislike here to allow you to miss home...because you like burgers it doesn't mean you dislike Russian vegetable soup. You can be open to society here but still keep the bond with Mum and friends back home...accepting something else doesn't mean you exclude something you had before... (Eva, female student, Eastern Europe)

...I like music, I like fashion...I like anything that brings life...I know how to rap and I know how to make beats...so I go to shows and I get to, like rap to people and connect with friends I don't even know before...I've been here for two years, I've been able to adapt to the culture, I've been able to learn a lot of things, seen a lot of places...I'm two different people now...I don't feel like I'm from a different place...I feel like this is home for me. (Jamal, male student, Africa)

\section{‘Cosmopolitanisation': 'Unconscious Cosmopolitans' and 'Resilient Thinkers'}

The thesis of cosmopolitanisation suggests that cosmopolitanism has actually come to exist in the practices of everyday life in an increasingly globalised world As global production and consumption transform the social landscape, cosmopolitanisation emerges as a process that is 
largely unintended and unforeseen, producing 'unconscious cosmopolitans' who assume an open orientation without normative intentions (Beck, 2002; Beck and Sznaider, 2006; Jacubowicz, 2011; Saito, 2011; Woodman, 2009). Rather, they welcome difference and the constant transformative effects of intercultural interactions that are the product of selfreflexivity (Barrett et al., 2011; Beck, 2002; Hedetoft, 2011, Nagata, 2004). 'Unconscious cosmopolitanism' is paralleled in notions of 'resilient thinking': a form of 'creative problem solving' that harnesses the ability to see and consider different points of view and to continue with daily life despite obstacles. For resilient thinkers, encounters with other cultures can bring new understanding, shifting mind-sets, building positive self-image, reducing risk factors and thereby opening up new opportunities and worldviews (Gunnestad, 2006; Gunnestad et al., 2010).

The testimony of ten students (almost 50\%) evidences epistemological boundaries and constraints dissolved, new sense of identity and new ways of viewing and engaging with the world. For some the change is very personal and profound:

...I put my background ideology away and I start to build very clean ideologies, not been affected by the régime in [Middle Eastern country]...I am ready to hear from everybody, discuss everybody, respect everybody and this is the biggest achievement...I feel myself a new person now... I came here full of pressure inside me... because I grow up in conflict... Before I used to be very angry if I am told that I am wrong ...but now...I discuss maybe with you and you show me that I am wrong, I will be very happy. (Abdo, male student, Middle East)

'...out of me and my sister I used to be the quite timid one...coming to uni. it meant that I was out of her shadow...but I turned into...a complete opposite of myself...really loud...I've realised I've got... an inner strength and I don't have to be loud... to be noticed...I found out that I'm not going to get on with everyone who I meet, but that's OK, I found out that I am...too much of a people pleaser but now I've just limited myself to being a people pleaser to those who actually matter. (Naledi, female student, Africa)

\section{An Alternative Pedagogy for Global Citizenship}

The stories told by participants reflect a process of cosmopolitanisation whereby the cosmopolitan has come to exist in individuals' every-day practices not by intention, but seemingly by a process of osmosis. In peering through the lens of resilience and resilient thinking it becomes clear that diverse students in the face of cultural dissonance, draw on resilient traits and personal characteristics to establish contact points with the host culture. As 'resilient thinkers' they discover 'key moments' and 'local truths' in their lives. They adapt and transform to reach new frontiers of development and domains of stability. Rather than either reducing the foreign to self or despairing of ever understanding 'other' - a place where there is no contact - diverse students can develop the openness of the 'in-between point of 
contact', a place of mediation that resists the safety of one-sidedness in favour of the constant re-negotiation of 'self' in the light of 'other' (Gadamer, 2004).

As far as global citizenship education is concerned, it is argued that rather than focus almost exclusively on international outward mobility, the higher education sector needs to avert its gaze towards the constant and emergent formation and deconstruction of identities and the development of multiple perspectives about the world that are the essential components of life and citizenship in a pluralistic, interconnected and complex world (Barrett et al., 2011; Beck, 2002; Fazey 2010; Pearl, 2010). This paper, therefore, proposes an alternative pedagogy for global citizenship education, which is integrative and participative, drawing on cultural biography and storytelling, as the raw material to theorise about global citizenship and reconfigure notions of openness as a jointly-authored search for intercultural understanding (Orange, 2011).

Storytelling may be perceived as lightweight, soft, and tantamount to therapeutic education that allows personal ideas to seep into the curriculum. However, it is becoming more popular in higher education as evidenced by contributions to the 'Storyville: exploring narratives of Learning and Teaching', Second Higher Education Academy Arts and Humanities Conference, Brighton, 29-30 May 2013. Cultural biography, which develops a self-analytical story of an individuals' life and the factors that have shaped who they are, has the power to convey an important message that people do not have to be the same or perfect. Sharing stories in dialogue can create powerful bonds of trust and openness through a process of revealing the person behind the label, disclosure that enables other students to construct their own new understandings of the cultural 'other' also promotes self-understanding. Gadamer (2004) used the metaphor of a fusion of horizons to show how the assumptions, prejudices, expectations and ideas that each interlocutor brings to dialogue (their horizon) limit thinking and understanding but contact with others' assumptions (their horizon) is enabling, acting as leverage for greater self-understanding and ultimately the formation of new horizons (Alterio, 2003; Gadamer, 2004; McGarry and Keating, 2010; Wright and Ashwin, 2011).

Wright and Ashwin (2011) show how sharing experiences of living in Britain can minimise the incidence of cultural marginalisation making it easier for students to discuss potentially sensitive issues relating to race, class, intellect and identity, discussions that are vital in the context of global citizenship education. However, the challenge lies in creating the right environment to use stories in a thoughtful reflective and formalised way, avoiding the selfjustification and trivialisation that can reduce discussion to a chat show. The ethical implications of developing this pedagogical approach suggest a level of academic support that may well require a strategic policy shift. For example, the tutor needs to be careful in facilitating discussion to ensure the 'pooling of knowledge' rather than the 'pooling of ignorance'; the 'disclosure effect' needs to be handled sensitively and requires neutralisation of the power differential between lecturer and learner through the sharing of personal life history. Students also require support in establishing ground rules for confidentiality within the group and protecting the identity of key players in stories. One of the most important ethical principles is students' personal rights to privacy but it is equally important to 
acknowledge that some people are better at telling stories than others. The vocabularies, discourses and metaphors that individuals access depend upon experience and social positioning and no student should feel that they are not legitimate participants if they don't have a story that fits the dominant narrative form or content.

\section{Conclusion}

This paper has argued that current models of global citizenship education based on international student mobility privilege particular notions of cosmopolitanism and fail to acknowledge a process of cosmopolitanisation that is playing out on university campuses. Research findings of a study exploring students' journeys to and experiences of higher education in the context of resilience and resilient thinking show that cosmopolitanisation and resilience are symbiotic in the life trajectories of culturally diverse students. Student stories reveal how the challenges of cultural dis-location and dissonance are countered by harnessing resilient traits and support mechanisms to develop resilient thinking in a myriad of ways that enable adaptation and transformation, which reaches new frontiers of personal development and domains of stability.

Dismissing the cosmopolitan and the mobile in favour of the local and the fixed is not the contention here, rather it is suggested that global citizenship should be re-conceptualised as a concept embracing diversity, belonging, community and solidarity. The stories related by the 'cultural mediators' identified in this study suggest the existence of a rich source of lived experience in higher education which can, if handled sensitively in dialogue, be harnessed in developing students' intercultural understanding, which is a pre-requisite of global citizenship. Pedagogies of cultural biography and storytelling offer a pathway to global citizenship education re-focussed on understanding the inter-connectedness of diverse students' multiple identities and acknowledging that learning and personal journeys are codependent, mutually reinforcing and continuous.

\section{References}

Allport, G.W. (1979) The Nature of Prejudice (25 ${ }^{\text {th }}$ Anniversary Edition). Reading, MA: Addison-Wesley Publishing.

Alterio, M (2003) Using Storytelling to Enhance Student Learning. York: Higher Education Academy www.heacademy.ac.uk last accessed 26 September 2013.

Bennett, J. (2008) On Becoming a Global Soul: A Path to Engagement During Study Abroad. In Savicki, V. (Ed.) Developing Intercultural Competence and Transformation: Theory, Research and Application in International Education, Yarmouth, ME: Intercultural Press.

Barrett, M., Flood, C. and Eade, J. (2011) Nationalism, Ethnicity, Citizenship: Multidisciplinary Perspectives - An Introduction. In Barrett, M., Flood, C. and Eade, J. (Eds.) (2011) Nationalism, Ethnicity, Citizenship: Multidisciplinary Perspectives Newcastle-upon-Tyne: Cambridge Scholars Publishing.

Beck, U. (2006) Living in The World Risk Society. A Hobhouse Memorial Public Lecture, London, 15 February 2006 http://www.libertysecurity.org/IMG/pdf_Beck-2006.pdf last accessed 26 September 2013. 
Beck, U. (2002) The Cosmopolitan Society and its Enemies. Theory, Culture and Society, 19 (1-2), pp. 17-4.

Beck, U. \& Sznaider, N. (2006) Unpacking Cosmopolitanism for the Social Sciences: A Research Agenda. The British Journal of Sociology, 57 (1), pp. 1-23.

Bryant, D. (undated) Campus Compact: Educating Citizens, Building Communities. The Everyone, Everywhere: Global Dimensions of Citizenship. http://www.compact.org/resources/future-of-campus-engagement/the-everyoneeverywhere-global-dimensions-of-citizenship/4259/ last accessed 26 September 2013.

Caruana, V. and Ploner, J. (2010) Internationalisation and Equality and Diversity in Higher Education: Merging Identities London: Equality Challenge Unit (ECU) http://www.ecu.ac.uk/publications/internationalisation-and-equality-and-diversity-inhe-merging-identities last accessed 26 September 2013.

Chan, V. (2001) Readiness for Learner Autonomy: What Do Our Learners Tell Us? Teaching in Higher Education, 6 (4), pp. 505-18.

Chen, G. M. and Starosta, W. J. (2000) The Development and Validation of

the Intercultural Communication Sensitivity Scale. Human

Communication, 3, pp. 1-15.

Denzin, N. K. (1989) Interpretive Interactionism. Newbury Park: Sage.

Fazey, I. (2010) Resilience and Higher Order Thinking. Ecology and Society, 15 (3), p. 9 http://www.ecologyandsociety.org/vol15/iss3/art9/ last accessed 26 September 2013

Gadamer, H-G. (2004) Truth and Metho. Translated by Joel Weinsheimer and Donald G. Marshall. New York: Continuum.

Gunnestad, A. (2006) Resilience in a Cross-Cultural Perspective. How Resilience is Generated in Different Cultures, Journal of Intercultural Communication Issue 11 (April 2006) http://www.immi.se/intercultural/nr11/gunnestad.htm last accessed 26 September 2013.

Gunnestad, A., Larsen, A.M. and Nguluka, S. (2010) Resilience in Minorities Journal of Intercultural Communication 22, http://www.immi.se/intercultural/nr22/gunnestad22.htm last accessed 26 September 2013.

Harrison, N. and Peacock, N. (2010) Cultural Distance, Mindfulness and Passive Xenophobia: Using Integrated Threat Theory to Explore Home Higher Education Students' Perspectives on 'Internationalisation at Home. British Educational Research Journal, 36 (6), pp. 877-902.

Hannerz, U. (2006) Two Faces of Cosmopolitanism: Culture and Politics. Documentos CIBOD, Serie: Dinamicas Interculturales Numero 7.

Hedetoft, U. (2011) 'Is Nationalism an Anachronism? Notes on the Mutations of National Idealism in a Global Age’. In Barrett, M., Flood, C. and Eade, J. (eds.) (2011) Nationalism, Ethnicity, Citizenship: Multidisciplinary Perspectives Newcastle-uponTyne: Cambridge Scholars Publishing.

Henderson, S., Holland, J., McGrellis, S., Sharpe, S., and Thomson, R. (2007) Inventing Adulthoods: A Biograohical Approach to Youth Transitions. London: Sage.

Holliday, M. and West, L. (2010) The Sociology of Reproduction and the Psychosociality of Transformation: Transitional Space, Object Relations and Les 'Miraculés' in Higher Education. Paper presented at the 40th Annual SCUTREA conference, 6-8 July 2010, University of Warwick, Coventry, http://www.leeds.ac.uk/educol/documents/191554.pdf accessed 26 September 2013 Jakubowicz, A. (2011) Playing the triangle: Cosmopolitanism, Cultural Capital and Social Capital as Intersecting Scholarly Discourses About Social Inclusion and 
Marginalisation in Australian Public Policy Debates. Cosmopolitan Civil Societies Journal, 3 (3), pp.68-91.

Killick, D. (2012) Seeing ourselves-in-the-world: Developing Global Citizenship Through International Mobility. Journal of Studies in International Education, 16 (4), pp. 37289.

King, R., Findlay, A. and Ahrens, J. (2010) International Student Mobility Literature Review, Report to HEFCE, and co-funded by the British Council, UK National Agency for Erasmus, London: HEFCE.

Luthar, S (2003), ed., Resilience and Vulnerability: Adaptation in the Context of Childhood Adversities. New York: Cambridge University Press

Marshall, H. (2009) Educating the European Citizen in the Global Age: Engaging with the Post-national and Identifying a Research Agenda. Journal of Curriculum Studies, 41 (2), pp. 247-67.

McGarry, R. and Keating, M. (2010) 'Auto/Biography, Personal Testimony and Epiphany Moments: a Case Study in Research-Informed Teaching' Enhancing Learning in the Social Sciences, 3 (1)

http://journals.heacademy.ac.uk/doi/full/10.11120/elss.2010.03010004 last accessed 4 October 2013.

Mercer, J.C. (2013) College Students’ Resilience: Selected Effects of Service Learning. University of North Texas Digital Library http://digital.library.unt.edu/ark:/67531/metadc30495/m1/10/ last accessed 26 September 2013.

Nagata, A.L. (2004) Promoting Self-Reflexivity in Intercultural Education, Journal of Intercultural Communication, 8, pp. 139-67.

Orange, D.M. (2011) The Suffering Stranger: Hermeneutics for Everyday Clinical Practice. London: Routledge.

Parrish, P. and Linder-Van Berschot, J.A. (2010) Cultural Dimensions of Learning: Addressing the Challenges of Multicultural Instruction. The International Review of Research in Open and Distance Learning, 11(2). http://www.irrodl.org/index.php/irrodl/article/view/809/1497 last accessed 4 October 2013.

Pearl, P. (2010) Five Key Principles of Mental Toughness and Resilience, http://ezinearticles.com/?expert=Phil_Pearl last accessed 26 September 2013.

Pieterse, J.N. (2006) Emancipatory Cosmopolitanism: Towards an Agenda. Development and Change, 37 (6), pp. 1247-57.

Reivich, K. and Shattle, A. (2002) The Resilience Factor. New York: Broadway Books

Rhodes, G., Kiyama, J.M., McCormick, R. and Quiroz, M. (2008) Local Cosmopolitans and Cosmopolitan Locals: New Models of Professionals in the Academy. The Review of Higher Education, 31 (2), pp. 209-35.

Saito, H. (2011) An Actor-Network Theory of Cosmopolitanism. Sociological Theory, 29 (2), pp. 124-49.

Schattle, H. (2007) The Practices of Global Citizenship. Lanham, Maryland: Rowman and Littlefield.

Savicki, V. and Selby, R. (2008) Synthesis and Conclusions. In Savicki, V. (ed.) Developing Intercultural Competences and Transformation: Theory, Research and Application in International Education, Sterling, Virginia: Stylus.

Shannon-Little, T. (2013) Thriving as an International Student: Personal Responses and the Trajectories They Create. Journal of Pedagogic Development, 2 (1), http://www.beds.ac.uk/learning/support/jpd/volume-2-issue-1/thriving-as-an- 
international-student-personal-responses-and-the-trajectories-they-create last accessed 26 September 2013

Skirbis, Z., Kendall, G. and Woodward, I. (2004) Locating Cosmopolitanism: Between Humanist Ideal and Grounded Social Category. Theory, Culture \& Society, 21 (6), pp. $115-36$.

Szerszynski, B. and Urry, J. (2002) Cultures of Cosmopolitanism. The Sociological Review, 50 (4), pp.461-481

Ting-Toomey, S. and Chung, L.C. (2012) Understanding Intercultural Communication, London: Oxford University Press.

Thomas, R., Holland, J., McGrellis, S., Henderson, S.J. and Sharpe, S. (2006) Inventing Adulthoods: A Biographical Approach to Youth Transitions, London: Sage.

Thomson, R. and Taylor, R. (2005) 'Between Cosmopolitanism and the Locals: Mobility as a Resource in the Transition to Adulthood'. Young, 13 (4), pp. 327-42.

Ungar, M. (2003) Qualitative Contributions to Resilience Research. Qualitative Social Work, 2 (1), pp. 85-102.

Volet, S. and Ang, G. (1998) Culturally Mixed Groups on International Campuses: An Opportunity for Intercultural Learning. Higher Education Research and Development, 17, pp. 5-23.

Walker, C., Gleaves, A. and Grey, J. (2006) Can Students Within Higher Education Learn to be resilient and, educationally speaking, does it matter? Educational Studies, 32 (3), pp. 251-64.

Westrick, J.M. (2005) Phenomenology and Meaning Making: Student Voices and Understandings of Cultural Difference. Journal of Studies in International Education, 9 (2), pp. 105-20

Woodman, D. (2009) The Mysterious Case of the Pervasive Choice Biography: Ulrich Beck, Structure/Agency and the Muddling State of Theory in the Sociology of Youth. Journal of Youth Studies, 12 (3), pp. 243-56.

Wright, H. and Ashwin, P. (2011) Questioning the Relations Between Biography, Theory and Power in Biographical Teaching Methods: a Dialogue. Enhancing Learning in the Social Sciences, 3 (3), pp. 3-21.

Zaharna, R.S. (1989) Self-Shock: the Double-Binding Challenge of Identity. International Journal of Intercultural Relations, 13(4), pp. 501-25. 